\title{
Halogen-Bonded Guanine Base Pairs, Quartets and Ribbons
}

\author{
Nicholas J. Thornton and Tanja van Mourik *(D) \\ EaStCHEM School of Chemistry, University of St Andrews, North Haugh, St Andrews KY16 9ST, UK; \\ njthornton2@gmail.com \\ * Correspondence: tanja.vanmourik@st-andrews.ac.uk
}

Received: 14 August 2020; Accepted: 4 September 2020; Published: 8 September 2020

\begin{abstract}
Halogen bonding is studied in different structures consisting of halogenated guanine DNA bases, including the Hoogsteen guanine-guanine base pair, two different types of guanine ribbons (R-I and R-II) consisting of two or three monomers, and guanine quartets. In the halogenated base pairs (except the Cl-base pair, which has a very non-planar structure with no halogen bonds) and R-I ribbons (except the At trimer), the potential $\mathrm{N}-\mathrm{X} \bullet \bullet \bullet \mathrm{O}$ interaction is sacrificed to optimise the $\mathrm{N}-\mathrm{X} \bullet \bullet \mathrm{N}$ halogen bond. In the At trimer, the astatines originally bonded to N1 in the halogen bond donating

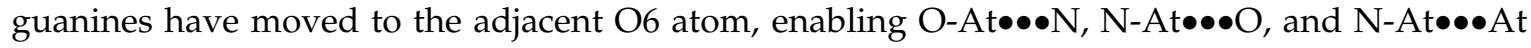
halogen bonds. The brominated and chlorinated R-II trimers contain two $\mathrm{N}-\mathrm{X} \bullet \bullet \bullet \mathrm{N}$ and two $\mathrm{N}-\mathrm{X} \bullet \bullet \bullet \mathrm{O}$ halogen bonds, whereas in the iodinated and astatinated trimers, one of the $\mathrm{N}-\mathrm{X} \bullet \bullet \bullet \mathrm{N}$ halogen bonds is lost. The corresponding R-II dimers keep the same halogen bond patterns. The G-quartets display a rich diversity of symmetries and halogen bond patterns, including $\mathrm{N}-\mathrm{X} \bullet \bullet \bullet \mathrm{N}, \mathrm{N}-\mathrm{X} \bullet \bullet \bullet \mathrm{O}, \mathrm{N}-\mathrm{X} \bullet \bullet \bullet \mathrm{X}$, $\mathrm{O}-\mathrm{X} \bullet \bullet \bullet \mathrm{X}$, and $\mathrm{O}-\mathrm{X} \bullet \bullet \bullet \mathrm{O}$ halogen bonds (the latter two facilitated by the transfer of halogens from $\mathrm{N} 1$ to O6). In general, halogenation decreases the stability of the structures. However, the stability increases with the increasing atomic number of the halogen, and the At-doped R-I trimer and the three most stable At-doped quartets are more stable than their hydrogenated counterparts. Significant deviations from linearity are found for some of the halogen bonds (with halogen bond angles around $\left.150^{\circ}\right)$.
\end{abstract}

Keywords: guanine-guanine base pair; guanine ribbons; guanine quartet; density functional theory; dispersion correction

\section{Introduction}

The last two decades have seen a huge upsurge in studies on halogen bonding, with overview articles and reviews also appearing in the literature [1-7]. A halogen bond is a type of $\sigma$-hole interaction, where a nucleophile interacts with the positively charged region (dubbed the $\sigma$-hole) at the extent of the $\mathrm{R}-\mathrm{X}$ bond, where $\mathrm{X}$ is the halogen and $\mathrm{R}$ is typically $\mathrm{C}$ but can also be another atom. Usually, the halogen is covalently bonded to one atom, but it has been shown that halogen-bonded complexes can also be formed with molecules where the halogen is bonded to two carbon atoms [8]. Halogen bonding plays important roles in many aspects of chemistry and biology, including material science [9], molecular crystals [10], biological molecules [11], and molecular recognition [12].

Halogen bonding has promising applications in synthetic DNA. As the four canonical DNA bases, adenine (A), guanine (G), cytosine (C), and thymine (T), are the "letters" of the "genetic alphabet", incorporating halogenated bases could extend this alphabet, which may allow engineering of novel artificial proteins or nucleic acids. However, not many studies exist on halogen bonding in nucleic acid structures. A density functional theory study at the B3LYP [13-15] level has shown that modified DNA bases can form halogen-bonded base pairs [16]. The authors considered canonical adenine-thymine 
(AT) and guanine-cytosine (GC) base pairs with either all or one of the hydrogens involved in hydrogen bonding replaced by $\mathrm{Cl}, \mathrm{Br}$, or I. They found that nearly all of the substituted base pairs form co-planar structures with favourable interaction energies. Another computational study on halogen bonds in nucleic acids using the ONIOM (Our own N-layered Integrated molecular Orbital

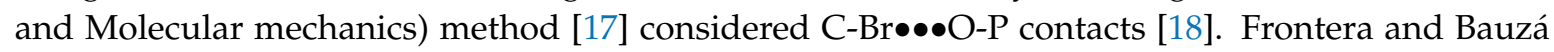
showed through a PDB (protein data bank [19]) survey coupled with MP2 (second-order Møller-Plesset perturbation theory [20]) calculations that halogenated nucleic acids can form halogen bonds with protein residues [21]. Other PDB surveys considered halogen bonding in biomolecules including nucleic acids [11,22]. An experimental study demonstrated that a halogen bond formed between a brominated uracil and phosphate oxygen can be engineered in a four-stranded DNA junction [23]. In the current study, we investigate halogen bonding in guanine base pairs, quartets, and ribbons. The inspiration for this study came from a recent computational study by Paragi and Fonseca Guerra on the self-assembly of guanine nucleobases into quartet and ribbon structures [24]. The study relates to scanning tunnelling microscopy (STM) experiments where guanine molecules were shown to form tetramer ring structures on a gold surface; however, these ring structures rearranged into ribbon-like structures when heated up [25]. Two different ribbon patterns were observed: one where the ribbons contain an $\mathrm{N}-\mathrm{H} \bullet \bullet \bullet \mathrm{N}$ and an $\mathrm{N}-\mathrm{H} \bullet \bullet \bullet O$ hydrogen bond between the guanine monomers (type I) and one where there are alternatively two $\mathrm{N}-\mathrm{H} \bullet \bullet \bullet \mathrm{N}$ hydrogen bonds or two $\mathrm{N}-\mathrm{H} \bullet \bullet \bullet \mathrm{O}$ hydrogen bonds between adjacent guanine monomers (type II) [26-28]. We were intrigued to see if these quartets and ribbons would still exist if the hydrogen-bonding hydrogens would be replaced by halogens. We consider the halogens $\mathrm{Cl}, \mathrm{Br}, \mathrm{I}$, and At. We do not include F, as this halogen usually does not form halogen bonds [29]. This has been ascribed to the fluorine's large electronegativity and tendency to engage in sp hybridisation, with a resulting influx of negative charge into the region where the positive $\sigma$-hole would be [4,30]. As in our previous studies on halogen bonding systems [8,31-33], we include the radioactive element At as it may help to reveal trends in energy and properties with increasing halogen size. Astatine is the most polarisable of the halogens considered here [34]. The first experimental evidence of halogen bonding with astatine was provided in 2018 [35]. In 2020, a coupled experimental and computational approach identified a 1:1 adduct of $\mathrm{Bu}_{3} \mathrm{PO} \bullet \bullet A t I$ as the strongest astatine-mediated halogen bond found so far [36].

\section{Results and Discussion}

\subsection{Method Comparison}

Table 1 compares the interaction energies and selected geometrical parameters calculated at different levels of theory for the I1,I2-substituted R-I dimer.

Table 1. Interaction energies and BSSE (basis set superposition error) values (in $\mathrm{kJ} / \mathrm{mol}$ ) and selected geometrical parameters (distances in $\AA$; angles in degrees) of the I1,I2-substituted R-I dimer, calculated at different levels of theory.

\begin{tabular}{|c|c|c|c|c|c|c|c|}
\hline Geometry & Energy & $\Delta \mathrm{E}^{\mathrm{CP}}$ & BSSE & $R(I \bullet \bullet \bullet N)$ & $\mathrm{R}(\mathrm{I} \bullet \bullet \bullet \mathrm{O})$ & $\angle(\mathbf{N I} \bullet \bullet \bullet N)$ & $\angle(\mathrm{NI} \bullet \bullet \bullet \mathrm{O})$ \\
\hline BLYP-D3/SVP & BLYP-D3/SVP & -55.5 & -13.5 & 2.58 & 3.78 & 178 & 113 \\
\hline BLYP-D3/SVP & BLYP-D3/TZVP & -53.2 & -2.1 & & & & \\
\hline BLYP-D3/TZVP & BLYP-D3/TZVP & -53.0 & -2.0 & 2.61 & 3.94 & 177 & 110 \\
\hline BLYP-D3/SVP & B3LYP-D3/TZVP & -54.7 & -1.8 & & & & \\
\hline B3LYP-D3/TZVP & B3LYP-D3/TZVP & -53.2 & -1.7 & 2.60 & 3.98 & 177 & 107 \\
\hline
\end{tabular}

The dimer contains two potential halogen bonds: an $\mathrm{N}-\mathrm{I} \bullet \bullet \bullet \mathrm{N}$ interaction and an $\mathrm{N}-\mathrm{I} \bullet \bullet \bullet \mathrm{O}$ interaction (see Figure 2; upper part). Potential halogen bond distances and angles are included in Table $1(\mathrm{R}(\mathrm{I} \bullet \bullet \bullet \mathrm{N}) / \angle(\mathrm{NI} \bullet \bullet \bullet \mathrm{N})$ for the $\mathrm{N}-\mathrm{I} \bullet \bullet \bullet \mathrm{N}$ interaction and $\mathrm{R}(\mathrm{I} \bullet \bullet \bullet \mathrm{O}) / \angle(\mathrm{NI} \bullet \bullet \bullet \mathrm{O}$ for the $\mathrm{N}-\mathrm{I} \bullet \bullet \bullet \mathrm{O}$ interaction). Further discussion on whether these are proper halogen bonds can be found in Section 2.3 below. There are some geometrical differences between the structures optimised with BLYP-D3 and 
B3LYP-D3 coupled with the def2-TZVP basis set. In particular, the $\mathrm{R}(\mathrm{I} \bullet \bullet \bullet \mathrm{O})$ distance is shorter for the BLYP-D3/def2-SVP geometry optimisation. This is presumably due to the considerably larger BSSE, which brings the two monomers closer together. However, the effect on the interaction energy is negligible when computed using the TZVP level and we therefore decided to optimise structures with BLYP-D3/def2-SVP and calculate interaction energies with BLYP-D3/def2-TZVP.

\subsection{Hoogsteen Base Pair}

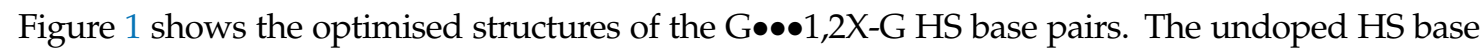
pair is not stable at the level of theory employed; it optimised to a $\mathrm{C}_{2}$-symmetric guanine base pair with $\mathrm{N}-\mathrm{H} \bullet \bullet O \mathrm{O}$ hydrogen bonds (see Figure 1). The halogenated base pairs all have $\mathrm{C}_{1}$ symmetry. The $\mathrm{Cl}$-doped base pair is very non-planar. It contains an $\mathrm{N}-\mathrm{H} \bullet \bullet \bullet O$ hydrogen bond but no halogen bonds. The dimers with the heavier halogens are also non-planar but show potential halogen bonds. Their structures retain the Hoogsteen bonding pattern. All have interaction energies smaller than that for the corresponding undoped base pair. Table 2 lists the potential halogen bond distances and angles, as well as their vdW ratios. The vdW ratios are well below 1 for the three $\mathrm{X} \bullet \bullet \bullet N$ interactions $(X=B r, I, A t)$, just below 1 for the $\mathrm{Br} \bullet \bullet O$ interaction, and above 1 for the $\mathrm{I} \bullet \bullet \bullet \mathrm{O}$ and At $\bullet \bullet \bullet$ interactions. This correlates with the nearly linear $\angle(\mathrm{NX} \bullet \bullet \mathrm{N})$ and non-linear $\angle(\mathrm{NX} \bullet \bullet \bullet)$ angles. The very non-linear $\angle(\mathrm{NX} \bullet \bullet \bullet \mathrm{O})$ angles indicate that the $\mathrm{N}-\mathrm{X} \bullet \bullet \bullet \mathrm{O}$ interaction cannot be classified as a halogen bond in any of these base pairs. Thus, it appears that the structure of the halogenated base pairs results from optimisation of the $\mathrm{N}-\mathrm{X} \bullet \bullet \bullet \mathrm{N}$ halogen bond at the expense of the $\mathrm{N}-\mathrm{X} \bullet \bullet \bullet \mathrm{O}$ interaction. Optimisation of one halogen bond at the expense of another was also observed for the halogenated AT and CG base pairs [16]. The interaction energies of the Br- and I-doped base pairs (-34.1 and $-48.7 \mathrm{~kJ} / \mathrm{mol}$, respectively) are in the same order of magnitude as those of Parker et al.'s AT base pair with two hydrogens replaced by $\mathrm{Br}$ or I ( -39.8 and $-28.3 \mathrm{~kJ} / \mathrm{mol}$, respectively) [16]. However, in our case, the I-substituted base pair is more stable than the Br-substituted base pair.
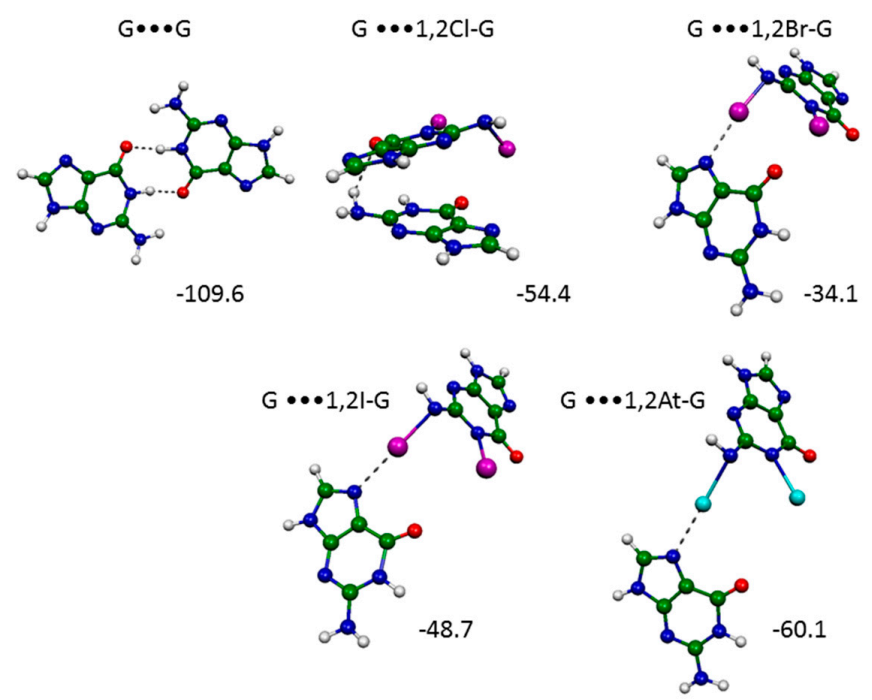

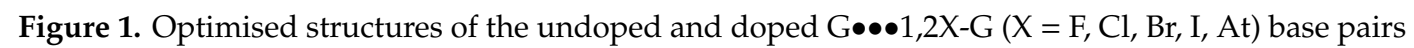
starting from Hoogsteen structures, with their interaction energies (in $\mathrm{kJ} / \mathrm{mol}$ ).

Table 2. Selected geometrical parameters (distances in $\AA$; angles in degrees) and van der Waals ratios $(\mathrm{vdW})$ for the $\mathrm{G} \bullet \bullet \bullet 1,2 \mathrm{X}-\mathrm{G}$ dimers $(\mathrm{X}=\mathrm{Br}, \mathrm{I}, \mathrm{At})$.

\begin{tabular}{|c|c|c|c|c|c|c|}
\hline System & $R(X \bullet \bullet N)$ & $\mathrm{R}(\mathrm{X} \bullet \bullet \bullet \mathrm{O})$ & $\operatorname{vdW}(\mathrm{X} \bullet \bullet N)$ & $\operatorname{vdW}(X \bullet \bullet \bullet O)$ & $\angle(\mathbf{N X} \bullet \bullet \bullet \mathbf{N})$ & $\angle(\mathbf{N X} \bullet \bullet \bullet)$ \\
\hline $\mathrm{G} \bullet \bullet \bullet 1,2 \mathrm{Br}-\mathrm{G}$ & 2.59 & 3.26 & 0.76 & 0.97 & 173.1 & 137.2 \\
\hline $\mathrm{G} \bullet \bullet \bullet 1,2 \mathrm{I}-\mathrm{G}$ & 2.60 & 3.99 & 0.74 & 1.14 & 179.5 & 122.3 \\
\hline$G \bullet \bullet \bullet 1,2 A t-G$ & 2.63 & 4.34 & 0.74 & 1.23 & 179.4 & 117.8 \\
\hline
\end{tabular}




\subsection{Ribbons $R-I$}

The R-I dimers and trimers are shown in Figure 2. Selected geometrical parameters and vdW ratios are given in Table 3. The unsubstituted dimer is a $\mathrm{C}_{2}$-symmetric reverse Hoogsteen base pair. It contains an $\mathrm{N}-\mathrm{H} \bullet \bullet \bullet \mathrm{N}$ and $\mathrm{N}-\mathrm{H} \bullet \bullet \bullet \mathrm{O}$ hydrogen bond. Bhattacharyya et al. calculated an interaction energy of $-65.0 \mathrm{~kJ} / \mathrm{mol}$ for this base pair with $\mathrm{HF} / 6-31 \mathrm{G}(\mathrm{d}, \mathrm{p})$ [37] and $-73.6 \mathrm{~kJ} / \mathrm{mol}$ at the B3LYP/6-31G(2d,2p) level [38], both smaller than the $-80.5 \mathrm{~kJ} / \mathrm{mol}$ calculated by us. This is presumably due to the missing correlation in the HF calculations and B3LYP's inability to account for dispersion effects [39]. Reverse Hoogsteen G-G and A-A base pairs were found to occur in homo-DNA (a DNA homologue with the standard $2^{\prime}$-deoxyribofuranose replaced by $2^{\prime}, 3^{\prime}$-dideoxyglucopyranose) [40,41]. Doping with halogens makes the dimers non-planar and reduces the symmetry to $C_{1}$. Like for the halogenated HS base pairs, the potential $\mathrm{N}-\mathrm{X} \bullet \bullet \bullet \mathrm{O}$ halogen bond has been sacrificed to optimise the $\mathrm{N}-\mathrm{X} \bullet \bullet \mathrm{N}$ halogen interaction, which is a proper halogen bond in all substituted dimers (vdW ratios below $0.8 ; \angle(\mathrm{NX} \bullet \bullet \bullet \mathrm{N})$ angles $\left.177-179^{\circ}\right)$. As for the HS base pair, the interaction energy of the Br-doped dimer $(-36.1 \mathrm{~kJ} / \mathrm{mol})$ is smaller, and that of the I-doped dimer larger $(-53.2 \mathrm{~kJ} / \mathrm{mol})$, than those of the AT base pair with two Br or I atoms, respectively [16]. The addition of a third guanine monomer leaves the geometry of the dimer unit qualitatively unchanged for the undoped trimer and the trimers with $\mathrm{Cl}$, Br, and I halogens (Table 3), with the $\mathrm{Cl}-, \mathrm{Br}-$, and I-doped trimers containing two $\mathrm{N}-\mathrm{X} \bullet \bullet \bullet \mathrm{N}$ and no $\mathrm{N}-\mathrm{X} \bullet \bullet \bullet \mathrm{O}$ halogen bonds. In the At-substituted trimer, however, the halogen bond pattern has changed. One of the astatines in the right and middle guanine moved from N1 to O6, creating two O-X $\bullet \bullet N$ halogen bonds (vdW ratios 0.73 and 0.69 and $\angle(\mathrm{OX} \bullet \bullet \bullet N)$ angles 170 and $\left.168^{\circ}\right)$ instead of $\mathrm{N}-\mathrm{X} \bullet \bullet \bullet N$ halogen bonds. The change in halogen bonding site in the right-most guanine molecule also allows an additional $\mathrm{N}-\mathrm{X} \bullet \bullet \bullet X$ halogen bond (vdW ratio 0.83 ; angle $177^{\circ}$ ) and the change from $\mathrm{N}-\mathrm{X} \bullet \bullet \bullet \mathrm{N}$ to $\mathrm{O}-\mathrm{X} \bullet \bullet \mathrm{N}$ halogen bond in the left dimer allows the formation of an $\mathrm{N}-\mathrm{X} \bullet \bullet \bullet \mathrm{O}$ halogen bond (vdW ratio 0.78 ; angle $161^{\circ}$ ). The interaction energies of the substituted trimers increase upon increasing the atomic number of the halogen. For the At-substituted trimer, we also calculated the interaction energy with respect to the constituent monomers, i.e., two 1,6-At-G and one 1,2-At-G molecules (value in brackets in Figure 2). This value shows how strongly the bases interact but ignores the energy required to deform two 1,2-At-G to 1,6-At-G molecules. For all trimers, the interactions are cooperative: $\mathrm{E}_{\text {coop }}$ is $-7.9,-2.9,-3,7,-9.6$, and $-32.7 \mathrm{~kJ} / \mathrm{mol}$ for the undoped, $\mathrm{Cl}-, \mathrm{Br}$, I-, and At-doped trimers, respectively (calculated using the interaction energies with respect to 1,2-X-G monomers). The large value for the At-substituted trimer shows a large increase in stability due to the additional halogen bonds facilitated by the transfer of two hydrogens from $\mathrm{N} 1$ to O6.

Table 3. Selected geometrical parameters (distances in $\AA$; angles in degrees) and van der Waals ratios (vdW) for the R-I dimers and trimers.

\begin{tabular}{|c|c|c|c|c|c|c|}
\hline System & $R(X \bullet \bullet N)$ & $\mathrm{R}(\mathrm{X} \bullet \bullet \bullet \mathrm{O})$ & $\operatorname{vdW}(X \bullet \bullet \bullet N)$ & $\operatorname{vdW}(X \bullet \bullet \bullet O)$ & $\angle(\mathbf{N X} \bullet \bullet \bullet \mathbf{N})$ & $\angle(\mathbf{N X} \bullet \bullet \bullet)$ \\
\hline$(1,2 \mathrm{Cl}-\mathrm{G})_{2}$ & 2.58 & 3.24 & 0.78 & 0.99 & 178 & 135 \\
\hline$(1,2 \mathrm{Br}-\mathrm{G})_{2}$ & 2.57 & 3.47 & 0.76 & 1.03 & 179 & 124 \\
\hline$(1,2 \mathrm{I}-\mathrm{G}) 3_{2}$ & 2.58 & 3.78 & 0.73 & 1.08 & 178 & 113 \\
\hline$(1,2 \text { At-G })_{2}$ & 2.60 & 3.74 & 0.73 & 1.06 & 177 & 111 \\
\hline$(1,2 \mathrm{Cl}-\mathrm{G})_{3}$ & $2.54 / 2.54$ & $3.47 / 3.35$ & $0.78 / 0.77$ & $1.06 / 1.03$ & $176 / 178$ & $125 / 135$ \\
\hline$(1,2 \mathrm{Br}-\mathrm{G})_{3}$ & $2.52 / 2.51$ & $3.45 / 3.34$ & $0.74 / 0.74$ & $1.02 / 0.99$ & $178 / 178$ & $124 / 126$ \\
\hline$(1,2 \mathrm{I}-\mathrm{G}) 3_{3}$ & $2.53 / 2.52$ & $3.76 / 3.67$ & $0.72 / 0.71$ & $1.07 / 1.05$ & $178 / 179$ & $109 / 116$ \\
\hline$(1,2 \mathrm{At}-\mathrm{G})_{3}$ & $2.52 / 2.47$ & $2.77 / 3.53$ & $0.73 / 0.69$ & $0.78 / 1.00$ & $143 / 146$ & $161 / 138$ \\
\hline
\end{tabular}



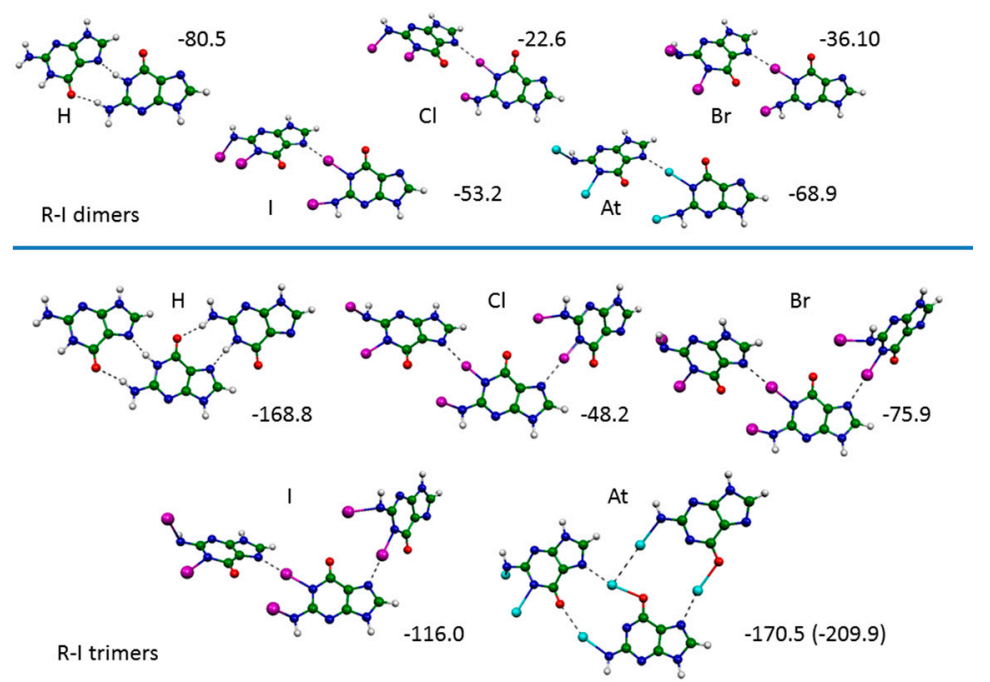

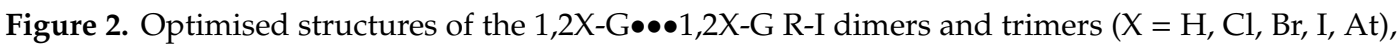
with their interaction energies (in $\mathrm{kJ} / \mathrm{mol}$ ). The interaction energy in brackets for the At-substituted trimer is calculated with respect to two 1,6At-G monomers and one 1,2At-G monomer.

\subsection{Ribbons $R-I I$}

Figure 3 shows the optimised R-II dimers and trimers, whereas selected geometrical parameters and vdW ratios have been collected in Table 4. In contrast to the R-I trimers, the R-II trimers contain two different constituent dimers: one containing two $\mathrm{N}-\mathrm{X} \bullet \bullet \bullet \mathrm{N}$ interactions (dimer 1 ) and one with two $\mathrm{N}-\mathrm{X} \bullet \bullet \bullet \mathrm{O}$ interactions (dimer 2). The R-II trimers were first optimised; subsequently, starting structures were obtained for the geometry optimisations of the dimers by removing one of the outermost guanines. The undoped dimer 1 has $C_{2}$ symmetry. It is non-planar, with the guanines twisted out of plane. It is the least stable of the three different guanine-guanine dimers considered in this work. Bhattacharyya et al. calculated an interaction energy of $-34.0 \mathrm{~kJ} / \mathrm{mol}$ for this base pair, at the B3LYP/6-31G $(2 \mathrm{~d}, 2 \mathrm{p})$ level [38], again smaller than the $-49.5 \mathrm{~kJ} / \mathrm{mol}$ calculated by us. The $\mathrm{Cl}$-dimer has $\mathrm{C}_{\mathrm{i}}$ symmetry. It is also non-planar, with a slight twist of one guanine accompanied by an opposite twist of the second guanine. The Br-dimer is planar with $\mathrm{C}_{2 \mathrm{~h}}$ symmetry. The I- and At-dimers have no symmetry elements. In the latter two, one $\mathrm{N}-\mathrm{X} \bullet \bullet \mathrm{N}$ interaction is optimised at the expense of the second one. For the R-II dimer 2, the undoped, I-, and At-substituted dimers have $\mathrm{C}_{2}$ symmetry, whereas the $\mathrm{Cl}$ - and $\mathrm{Br}$-substituted dimers have $\mathrm{C}_{\mathrm{i}}$ symmetry. The undoped dimer is a reverse Watson-Crick base pair. Such base pairs occur in RNA, contributing to its structural complexity [42]. Mitra et al. calculated an interaction energy of $-107.9 \mathrm{~kJ} / \mathrm{mol}$ for the reverse Watson-Crick GG base pair (with methyl groups at the 9-position) at the M05-2X/6-31G++(2d,2p) level of theory [43], close to our result of $-110.3 \mathrm{~kJ} / \mathrm{mol}$. All dimers 2 contain two symmetry-related $\mathrm{N}-\mathrm{X} \bullet \bullet \bullet \mathrm{O}$ halogen bonds. Again, the interaction energy of the Br-doped dimers (both 1 and 2) is smaller, and those of the I-doped dimers larger, than those of the AT base pair with two $\mathrm{Br}$ or I atoms, respectively [16]. The symmetry elements in the dimer disappear in the trimer. The undoped, $\mathrm{Cl}$-, and Br-containing trimers have clearly two $\mathrm{N}-\mathrm{X} \bullet \bullet \bullet \mathrm{N}$ and two $\mathrm{N}-\mathrm{X} \bullet \bullet \bullet \mathrm{O}$ halogen bonds. Like for the dimer 1, in the I- and At-trimer, one of the $\mathrm{N}-\mathrm{X} \bullet \bullet \bullet \mathrm{N}$ halogen bonds is sacrificed to optimise the other $\mathrm{N}-\mathrm{X} \bullet \bullet \bullet \mathrm{N}$ halogen bond. Unlike for the ribbons R-I, the interactions in the trimers are not always cooperative: $\mathrm{E}_{\mathrm{coop}}$ is $-1.9,1.4,-6.1,0.3$, and $-9.4 \mathrm{~kJ} / \mathrm{mol}$ for the undoped, $\mathrm{Cl}-, \mathrm{Br}-$, I-, and At-containing trimers, respectively. 

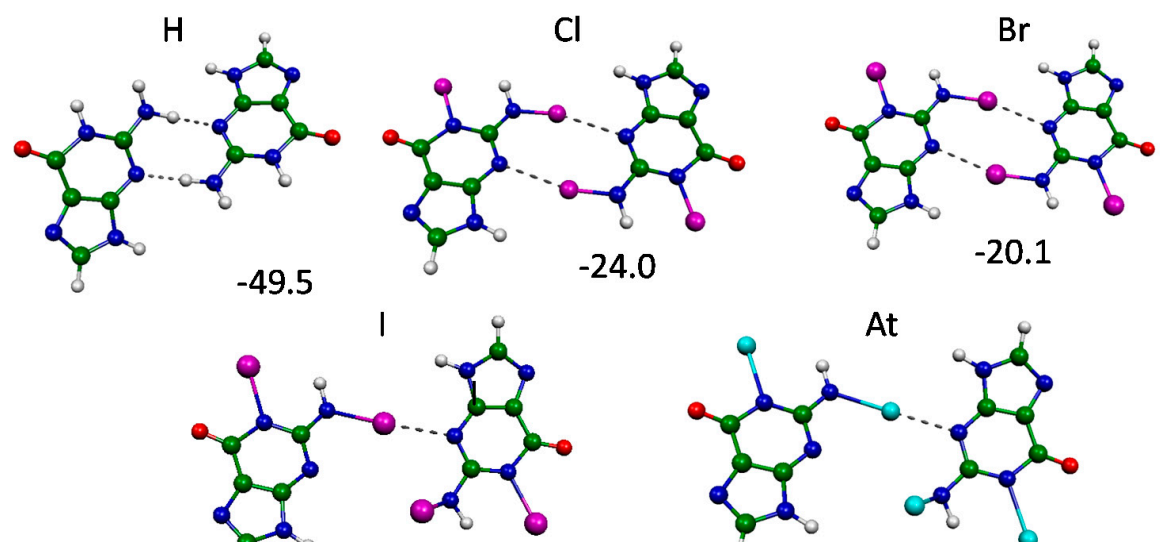

$-47.2$

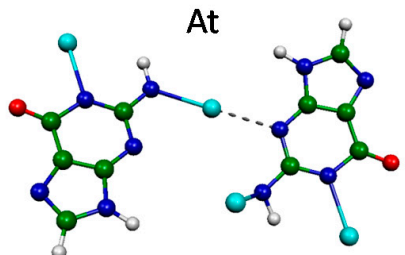

$-49.1$

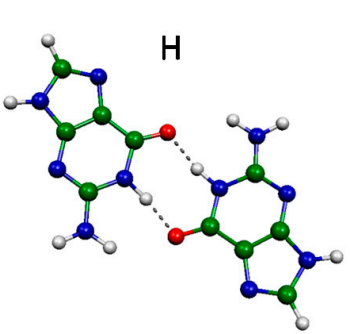

$-110.3$
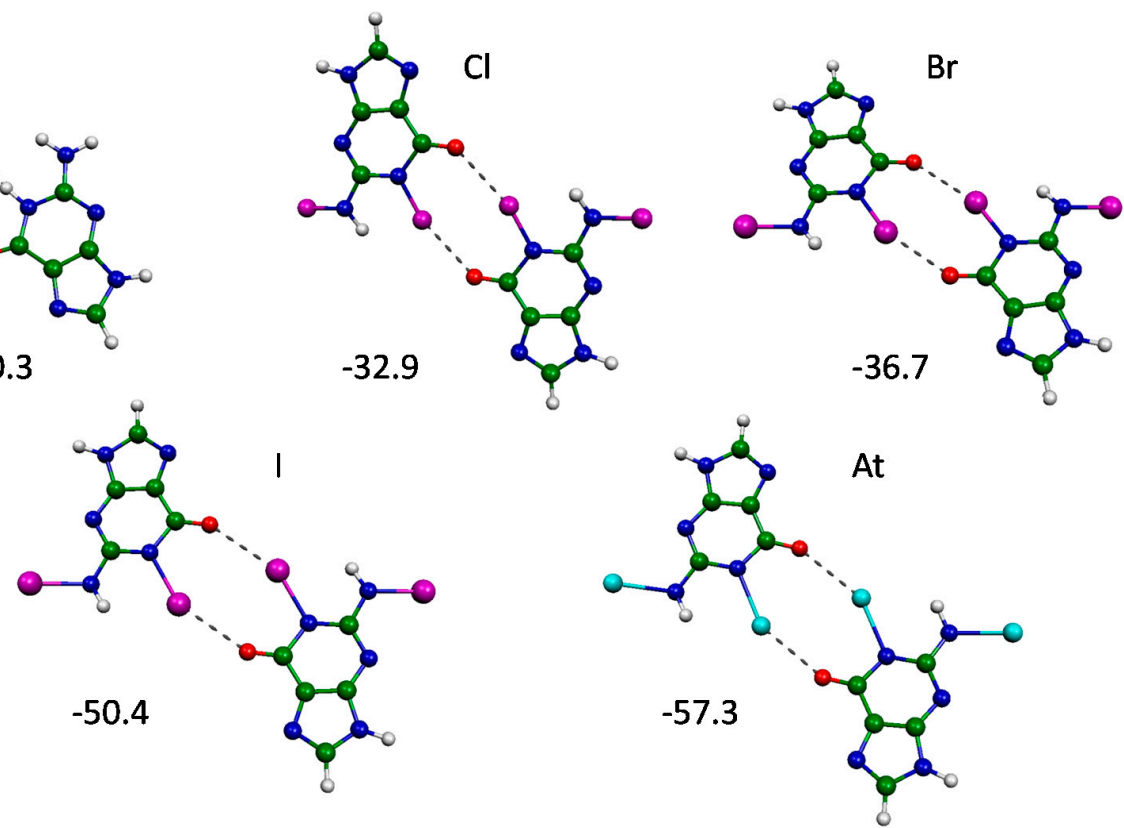

R-II dimers 2
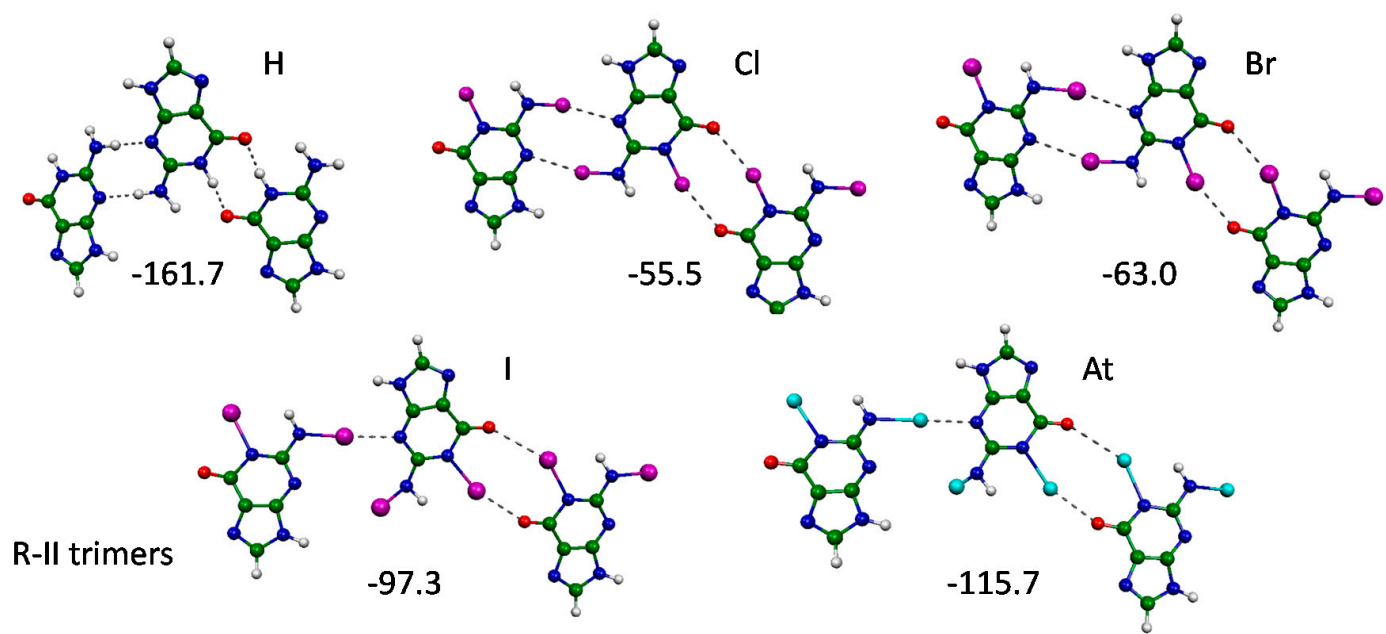

Figure 3. Optimised structures of the $1,2 \mathrm{X}-\mathrm{G} \bullet \bullet \bullet 1,2 \mathrm{X}-\mathrm{G}$ ribbon II dimers and trimers $(\mathrm{X}=\mathrm{H}, \mathrm{Cl}, \mathrm{Br}, \mathrm{I}$, At), with their interaction energies (in $\mathrm{kJ} / \mathrm{mol}$ ). 
Table 4. Selected geometrical parameters (distances in $\AA$; angles in degrees) and van der Waals ratios (vdW) for the R-II dimers and trimers.

\begin{tabular}{|c|c|c|c|c|c|c|}
\hline System & $R(X \bullet \bullet N)$ & $\mathrm{R}(\mathrm{X} \bullet \bullet \bullet O)$ & $\operatorname{vdW}(\mathrm{X} \bullet \bullet \bullet)$ & $\operatorname{vdW}(X \bullet \bullet \bullet)$ & $\angle(\mathbf{N X} \bullet \bullet \mathbf{N})$ & $\angle(\mathrm{NX} \bullet \bullet \bullet \mathrm{O})$ \\
\hline \multicolumn{7}{|l|}{ Dimer 1} \\
\hline$(1,2 \mathrm{Cl}-\mathrm{G})_{2}$ & 2.83 & & 0.86 & & 166 & \\
\hline$(1,2 \mathrm{Br}-\mathrm{G})_{2}$ & 2.85 & & 0.84 & & 163 & \\
\hline$(1,2 \mathrm{I}-\mathrm{G})_{2}$ & $2.65 / 4.52$ & & $0.75 / 1.28$ & & $177 / 97$ & \\
\hline$(1,2 \text { At-G })_{2}$ & $2.55 / 4.19$ & & $0.71 / 1.17$ & & $178 / 91$ & \\
\hline \multicolumn{7}{|l|}{ Dimer 2} \\
\hline$(1,2 \mathrm{Cl}-\mathrm{G})_{2}$ & & 2.75 & & 0.84 & & 166 \\
\hline$(1,2 \mathrm{Br}-\mathrm{G})_{2}$ & & 2.79 & & 0.83 & & 161 \\
\hline$(1,2 \mathrm{I}-\mathrm{G})_{2}$ & & 2.94 & & 0.84 & & 155 \\
\hline$(1,2 \text { At-G })_{2}$ & & 2.86 & & 0.81 & & 153 \\
\hline$(1,2 \mathrm{Cl}-\mathrm{G})_{3}$ & $2.86 / 2.81$ & $2.72 / 2.77$ & $0.87 / 0.85$ & $0.83 / 0.85$ & $165 / 167$ & $167 / 165$ \\
\hline$(1,2 \mathrm{Br}-\mathrm{G})_{3}$ & $2.82 / 2.85$ & $2.74 / 2.83$ & $0.83 / 0.84$ & $0.81 / 0.84$ & $165 / 160$ & $163 / 159$ \\
\hline$(1,2 \mathrm{I}-\mathrm{G})_{3}$ & $2.63 / 4.50$ & $2.73 / 3.23$ & $0.74 / 1.28$ & $0.78 / 0.92$ & $177 / 97$ & $153 / 147$ \\
\hline$(1,2 \text { At-G })_{3}$ & $2.56 / 4.16$ & $2.68 / 3.13$ & $0.72 / 1.17$ & $0.76 / 0.88$ & $178 / 91$ & $160 / 146$ \\
\hline
\end{tabular}

\subsection{G-Quartets}

G-quartets are structural motifs occurring in G-quadruplexes, which are higher-order DNA and RNA structures formed by sequences that are rich in guanine [44]. G-quartets consist of four guanine bases, interacting through Hoogsteen base pairing. Figure 4 shows the optimised structures of the $1,2 \mathrm{X}-\mathrm{G}$ quartets. Some selected geometrical parameters are available in the Supplementary Materials (Table S1).

We located two structures for the undoped G-quartet: an $\mathrm{S}_{4}$-symmetric quartet and a $\mathrm{C}_{4 \mathrm{~h}}$-symmetric quartet, both containing Hoogsteen GG base-pair hydrogen bonds. The $\mathrm{S}_{4}$ quartet is slightly more stable than the $\mathrm{C}_{4 \mathrm{~h}}$ quartet, in agreement with previous results $[45,46]$. The absence of imaginary frequencies indicates that the $\mathrm{S}_{4}$-symmetric quartet is a true minimum on the potential energy surface. We find one imaginary frequency for the $\mathrm{C}_{4 \mathrm{~h}}$ quartet, in agreement with previous calculations at the B3LYP/6-311G $(d, p)$ level [46] but in disagreement with the B3LYP/DZVP results of Meyer et al. [45], which found four imaginary frequencies. Unlike the previous studies, no quartet with bifurcated hydrogen bonds was located. Attempts to optimise such a structure resulted in the $\mathrm{S}_{4}$-symmetric quartet. Paragi and Fonseca Guerra calculated an interaction energy of $-331 \mathrm{~kJ} / \mathrm{mol}$ with BLYP-D and a basis set of triple-zeta quality [24], somewhat larger than our value of $320-322 \mathrm{~kJ} / \mathrm{mol}$. However, Paragi and Fonseca Guerra's result is not corrected for BSSE. We calculate BSSE values of -12 to $-13 \mathrm{~kJ} / \mathrm{mol}$ for the unsubstituted quartets, which accounts for most of the difference between our results and those of Paragi and Fonseca Guerra. It should also be noted that Paragi and Fonseca Guerra optimised the quartets with planar constraint to mimic the adsorption onto a gold surface.

For the $\mathrm{Cl}$-doped quartet, two $\mathrm{C}_{2}$-symmetric and two $\mathrm{C}_{4}$-symmetric structures were located. The most stable quartet $\left(\Delta \mathrm{E}^{\mathrm{CP}}=-105.6 \mathrm{~kJ} / \mathrm{mol}\right)$ is a $\mathrm{C}_{2}$-symmetric structure with a central $\mathrm{Cl} \bullet \bullet \bullet \mathrm{Cl}$ halogen bond (vdW ratio 0.88 ; but with $\angle \mathrm{N}-\mathrm{Cl} \bullet \bullet \bullet \mathrm{Cl}$ angles of $148^{\circ}$, on the border of being true halogen bonds) and four (two-by-two identical) $\mathrm{N}-\mathrm{Cl} \bullet \bullet \bullet \mathrm{N}$ halogen bonds (vdW ratios of 0.87 and 0.88 ; angles 166 and $156^{\circ}$, respectively). The next quartet $\left(\Delta \mathrm{E}^{\mathrm{CP}}=-81.0 \mathrm{~kJ} / \mathrm{mol}\right)$ has also $\mathrm{C}_{2}$ symmetry, and contains four (two-by-two symmetric) $\mathrm{N}-\mathrm{Cl} \bullet \bullet \bullet \mathrm{N}$ halogen bonds (all vdW ratios 0.76 ; angles 176 and $179^{\circ}$ ). It has a slight "bowl" structure. The $\mathrm{Cl} \bullet \bullet \bullet \mathrm{O}$ distances are too large to classify the $\mathrm{N} \mathrm{Cl \bullet \bullet \bullet O} \mathrm{interactions}$ as halogen bonds. The third most stable Cl-quartet $\left(\Delta \mathrm{E}^{\mathrm{CP}}=-63.9 \mathrm{~kJ} / \mathrm{mol}\right)$ is $\mathrm{C}_{4}$-smmetric. It has four symmetry-related $\mathrm{N}-\mathrm{Cl} \bullet \bullet \bullet \mathrm{N}$ halogen bonds (vdW ratio 0.87 ; angle $163^{\circ}$ ). Four $\mathrm{Cl}$ atoms form a square in the central cavity linked by $\mathrm{Cl} \bullet \bullet \bullet \mathrm{Cl}$ halogen bonds (vdW ratio $0.90 ; \angle \mathrm{N}-\mathrm{Cl} \bullet \bullet \bullet \mathrm{Cl} 174^{\circ}$ ). The fourth $\mathrm{Cl}$-quartet has a positive interaction energy when the energy of the 1,2Cl-G molecule is used as reference. In this quartet, the $\mathrm{Cl}$ atoms originally bonded to $\mathrm{N} 1$ have moved to the adjacent O6 oxygen. If the 1,6Cl-G monomer (with one $\mathrm{Cl}$ attached to $\mathrm{O} 6$ ) is used to calculate the interaction 
energy, it becomes negative $(-101.9 \mathrm{~kJ} / \mathrm{mol}$; number in brackets in Figure 2), showing that the bases interact favourably.

The most stable Br-containing quartet is $\mathrm{C}_{4}$-symmetric, with $\mathrm{N}-\mathrm{Br} \bullet \bullet \bullet \mathrm{O}$ hydrogen bonds (vdW ratio 0.80; angles $166^{\circ}$ ) and a square of four bromines in the centre forming $\mathrm{Br} \bullet \bullet \bullet \mathrm{Br}$ halogen bonds ( vdW ratio $\left.0.88 ; \angle \mathrm{N}-\mathrm{Cl} \bullet \bullet \bullet \mathrm{Br} 176^{\circ}\right)$. It is similar to the $\mathrm{Cl}$-quartet 3 . The second Br-quartet, which is similar to the $\mathrm{Cl}$-quartet 2, has $\mathrm{C}_{2}$ symmetry and four $\mathrm{N}-\mathrm{Br} \bullet \bullet \bullet \mathrm{N}$ halogen bonds (vdW ratios 0.71 and 0.72 ; angles 179 and $176^{\circ}$ ). The four $\mathrm{N}-\mathrm{Br} \bullet \bullet \bullet \mathrm{O}$ contacts are not halogen bonds: two have a vdW ratio above 1 and, whereas the other two have vdW ratios below 1 (0.92), their $\mathrm{N}-\mathrm{Br} \bullet \bullet \bullet \mathrm{O}$ angles $\left(101^{\circ}\right)$ are too far from linearity for halogen bonds. The third Br-quartet is $\mathrm{S}_{4}$-symmetric; the guanine bases are slightly twisted out-of-plane. It contains four symmetry-related $\mathrm{N}-\mathrm{Br} \bullet \bullet \mathrm{O}$ halogen bonds

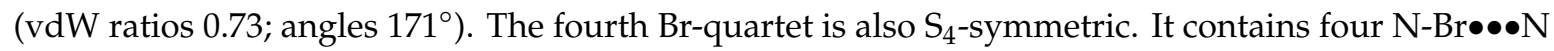
halogen bonds. The $\mathrm{N}-\mathrm{Br} \bullet \bullet \mathrm{O}$ contacts can just be considered proper halogen bonds with vdW ratios comfortably below $1(0.81)$ but with rather non-linear $\mathrm{N}-\mathrm{H} \bullet \bullet \bullet \mathrm{O}$ angles $\left(148^{\circ}\right)$. The fifth Br-quartet has $\mathrm{C}_{4}$ symmetry. It contains four $\mathrm{N}-\mathrm{Br} \bullet \bullet \bullet \mathrm{N}$ halogen bonds ( $\mathrm{vdW}$ ratio 0.77 ; angle $175^{\circ}$ ) and four bifurcated halogen bonds, consisting of one strong $\mathrm{O}-\mathrm{Br} \bullet \bullet \bullet B r$ halogen bond (vdW ratio 0.77; angle $169^{\circ}$ ) and a weaker $\mathrm{O}-\mathrm{Br} \bullet \bullet \bullet$ halogen bond (vdW ratio 0.95 ; angle $150^{\circ}$ ). The bromine atoms have moved from $\mathrm{N} 1$ to $\mathrm{O} 6$. The structure is similar to $\mathrm{Cl}$-quartet 4 , except that, in the latter, the $\mathrm{O}-\mathrm{Cl} \bullet \bullet \bullet \mathrm{O}$ interactions cannot be considered halogen bonds because of their vdW ratios above 1 (1.14).
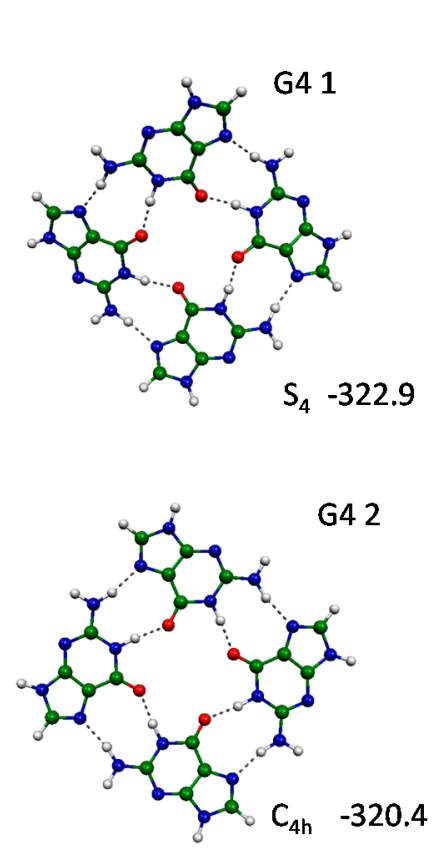
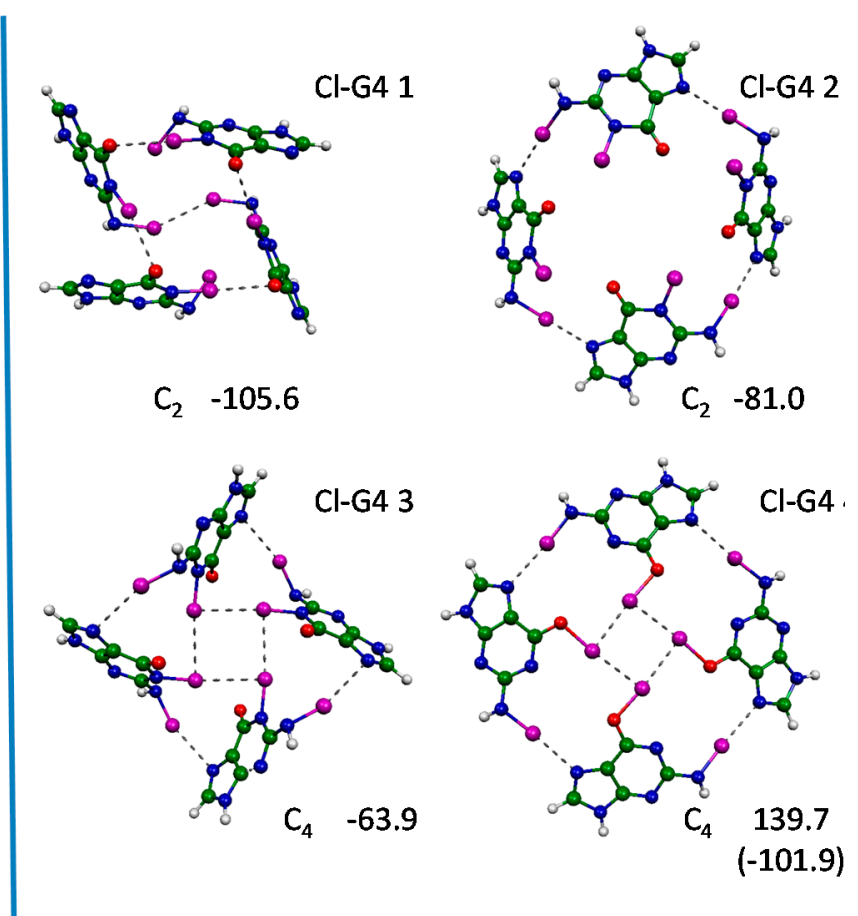

Figure 4. Cont. 


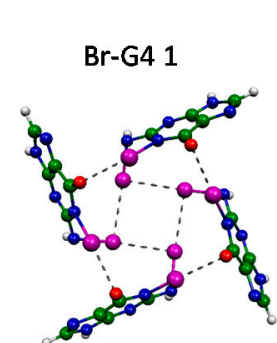

$C_{4} \quad-171.0$

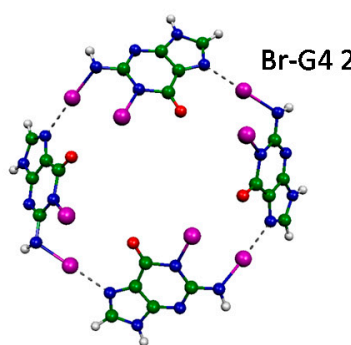

$c_{2} \quad-143.2$

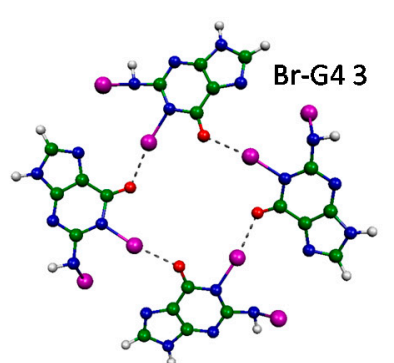

$S_{4} \quad-115.6$

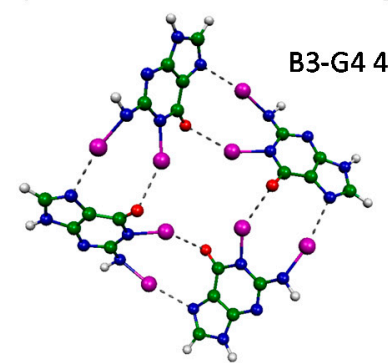

$\mathrm{S}_{4} \quad-105.0$

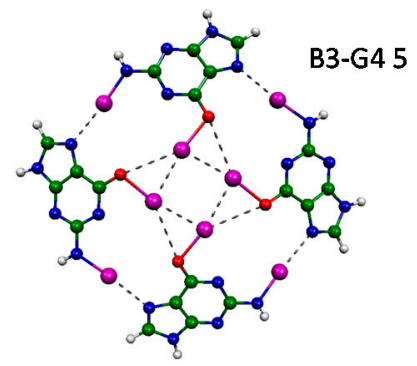

$\mathrm{C}_{4} \quad-55.2(-228.9)$

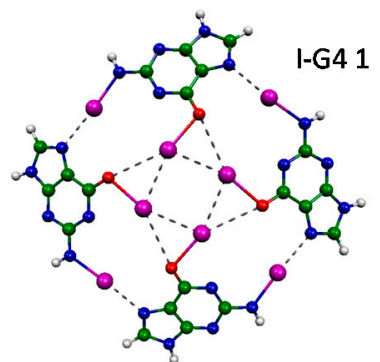

$\mathrm{C}_{4}-318.9(-414.1)$

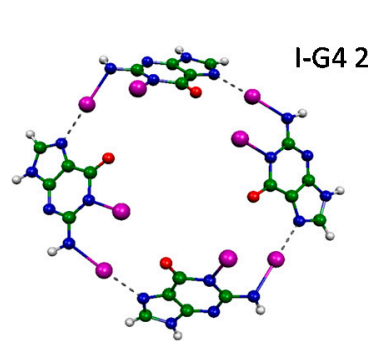

$C_{2} \quad-238.3$

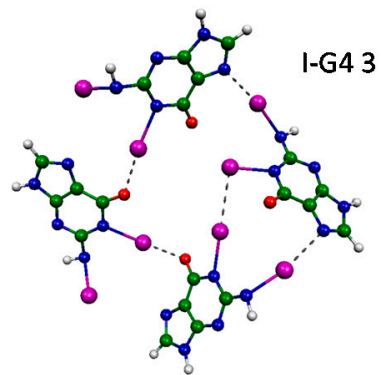

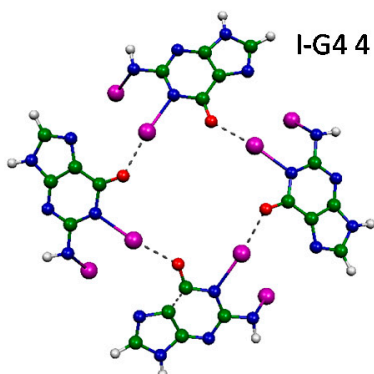

$C_{4}-219.1$

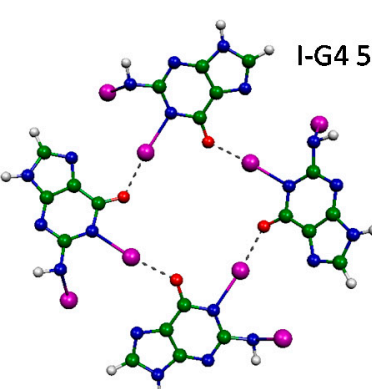

$c_{1}-219.0$
$C_{1}-221.3$

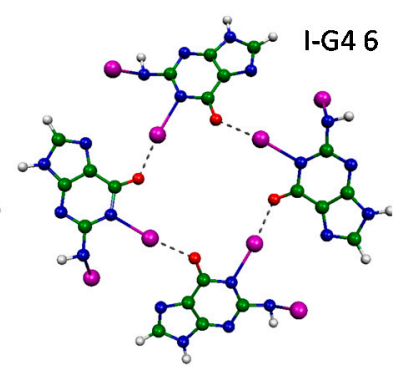

$S_{4}-218.8$

Figure 4. Cont. 

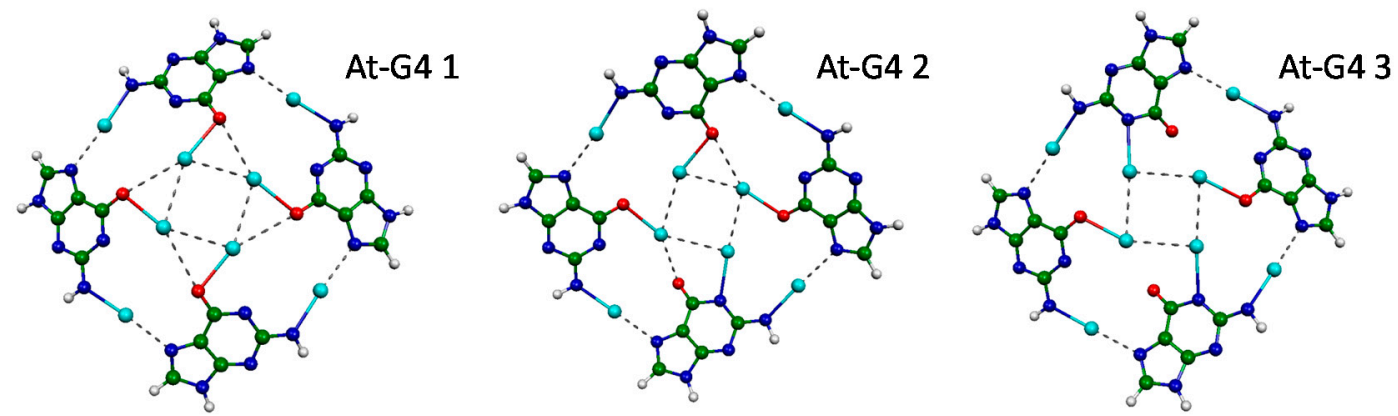

$C_{4} \quad-476.3(-555.1)$

$C_{1} \quad-462.1(521.2)$

$C_{2} \quad-453.0(-492.4)$

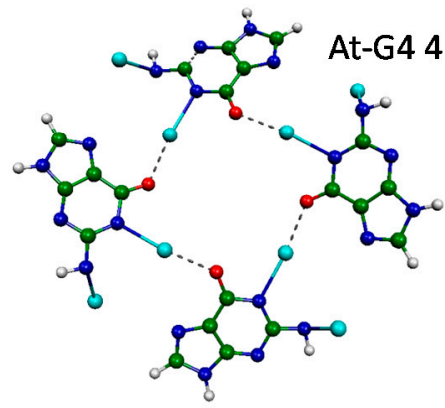

$\mathrm{S}_{4} \quad-306.8$

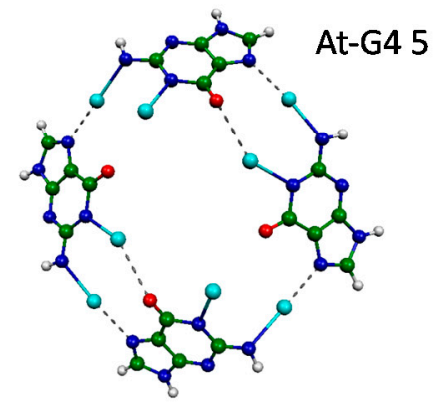

C. -302.8

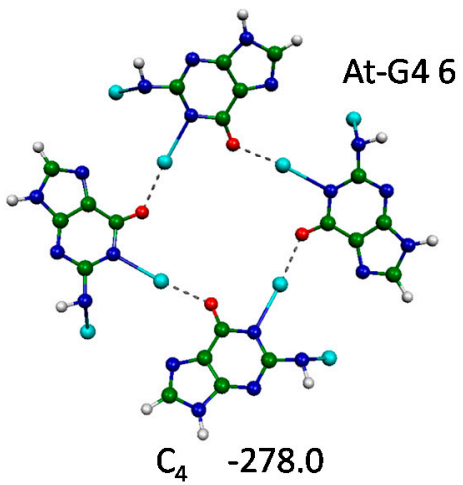

Figure 4. The optimised $\mathrm{X}$-quartets $(\mathrm{X}=\mathrm{Cl}, \mathrm{Br}, \mathrm{I}, \mathrm{At})$. The symmetry and interaction energy (in $\mathrm{kJ} / \mathrm{mol}$ ) are listed below the structure. The interaction energy in brackets is calculated with respect to four 1,6X-G monomers (for Cl-G4 4, Br-G4 5, and At-G4 1), three 1,6X-G monomers, and one 1,2X-G monomer (At-G4 2) or two 1,6X-G monomers and two 1,2X-G monomers (At-G4 3).

Like Br-quartet 5, the most stable I-quartet is $\mathrm{C}_{4}$-symmetric with four identical $\mathrm{N}$-I $\bullet \bullet \bullet \mathrm{N}$ halogen

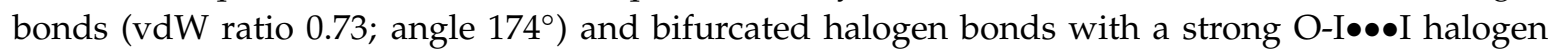

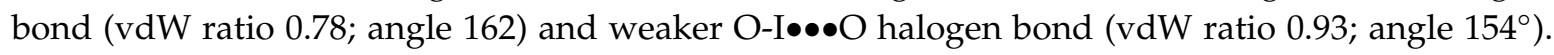
Like Cl-quartet 4 and Br-quartet 5, the halogen has moved from $\mathrm{N} 1$ to the adjacent O6. The next I-quartet is a $\mathrm{C}_{2}$-symmetric bowl-like structure with four (two-by-two symmetry-related) $\mathrm{N}-\mathrm{I} \bullet \bullet \bullet \mathrm{N}$ halogen bonds (vdW ratios 0.70 for all four bonds; angles $179^{\circ}$ and $177^{\circ}$ ). It is similar to Cl-quartet 2 and Br-quartet 2. The third I-quartet has no symmetry elements. Two of the $\mathrm{N}-\mathrm{I} \bullet \bullet \bullet \mathrm{N}$ interactions can be classified as halogen bonds (vdW ratios of 0.72 and 0.76 ; angles 170 and $168^{\circ}$ ). Moreover, two of the $\mathrm{N}-\mathrm{I} \bullet \bullet \bullet \mathrm{O}$ interactions are halogen bonds (vdW ratios 0.68 and 0.69 ; angles 178 and $174^{\circ}$ ), as well as one of the $\mathrm{N}-\mathrm{I} \bullet \bullet \bullet \mathrm{N}$ interactions ( $\mathrm{vdW}$ ratio 0.81 ; angle $177^{\circ}$ ). The fourth I-quartet has $\mathrm{C}_{4}$ symmetry. It contains four $\mathrm{N}-\mathrm{I} \bullet \bullet \bullet \mathrm{O}$ halogen bonds ( $\mathrm{vdW}$ ratios 0.68 ; angles $173^{\circ}$ ). The fifth most stable I-quartet has no symmetry elements. It contains four $\mathrm{N}-\mathrm{I} \bullet \bullet \bullet \mathrm{O}$ halogen bonds (vdW ratio 0.68-0.69; angle $173-175^{\circ}$ ). The sixth most stable I-quartet is $\mathrm{S}_{4}$-symmetric and contains four $\mathrm{N}-\mathrm{I} \bullet \bullet \bullet \mathrm{O}$ halogen bonds (vdW ratios 0.68 ; angles $173^{\circ}$ ). The last three I-quartets have similar energies; however, they differ slightly in structure. Whereas the iodines bonded to the amino group point alternatively up and down from the approximate plane of the molecule in the $\mathrm{C}_{1}$ and $\mathrm{S}_{4}$-symmetric structures, they point the same way in the $\mathrm{C}_{4}$-symmetric structure.

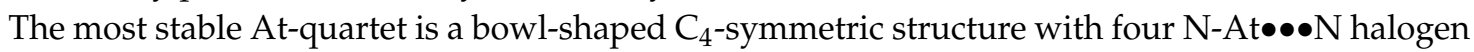

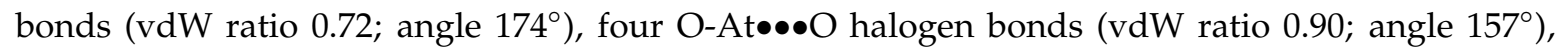
and four $\mathrm{O}-\mathrm{X} \bullet \bullet \bullet \mathrm{X}$ halogen bonds ( $\mathrm{vdW}$ ratio 0.79 ; angle $157^{\circ}$ ). The inner astatine atoms moved from $\mathrm{N} 1$ to O6. It is similar to $\mathrm{Cl}$-quartet 4 (even though this lacks proper $\mathrm{O}-\mathrm{Cl} \bullet \bullet \bullet O$ halogen bonds), Br-quartet 5, and I-quartet 1 . The next At-quartet does not have symmetry elements. It displays

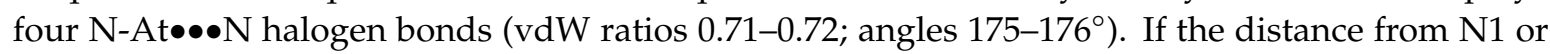
O6 to the halogen is used to determine which atom the astatine is bonded to, then, in three of the guanines, the inner At atom is bonded to O6, and in the fourth guanine, it is bonded to N1. There is 


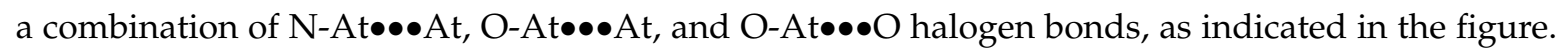

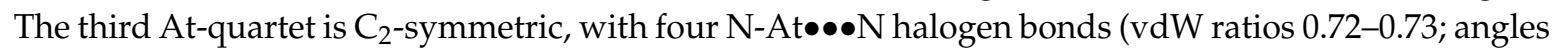

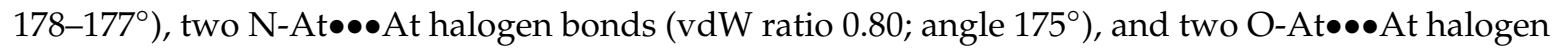

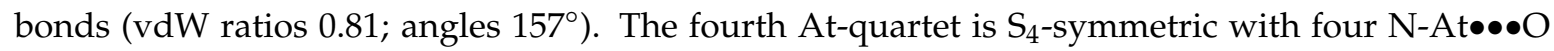
halogen bonds ( $\mathrm{vdW}$ ratio 0.68 ; angle $173^{\circ}$ ). The fifth At-quartet has $\mathrm{C}_{2}$ symmetry; it contains four

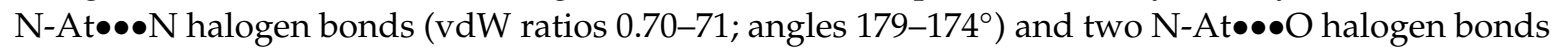
(vdW ratio 0.84 ; angle $\left.161^{\circ}\right)$. The last At-quartet is $\mathrm{C}_{4}$-symmetric with four $\mathrm{N}-\mathrm{At} \bullet \bullet \bullet \mathrm{O}$ halogen bonds (vdW ratio 0.69 ; angle $\left.175^{\circ}\right)$. At-quartets 4 and 6 have a similar structure; however, in the $\mathrm{S}_{4}$-symmetric structure, the astatines on the amino group are pointing alternatively up and down, whereas in the $\mathrm{C}_{4}$-symmetric structure, they point in the same direction.

Chlorination and bromination leads to less stable quartets. However, the most stable iodinated quartet has an interaction energy very close to the undoped quartet, and the three most stable astatinated quartets are more stable than the unsubstituted quartet.

\section{Methodology}

The structures considered include guanine-guanine (GG) base pairs with Hoogsteen (HS) base pairing, dimer and trimer ribbons with $\mathrm{N}-\mathrm{H} \bullet \bullet \bullet \mathrm{N}$ and $\mathrm{N}-\mathrm{H} \bullet \bullet \bullet \mathrm{O}$ hydrogen bonds between the monomers (R-I ribbons), dimer and trimer chains with two $\mathrm{N}-\mathrm{H} \bullet \bullet \bullet \mathrm{N}$ hydrogen bonds or two $\mathrm{N}-\mathrm{H} \bullet \bullet \bullet \mathrm{O}$ hydrogen bonds between the monomers (R-II ribbons), and G-quartets with Hoogsteen base pairing (see Scheme 1). Halogenated structures were created by replacing the hydrogens that form H-bonds in the GC base pair, i.e., the hydrogen attached to $\mathrm{N} 1$ and one of the hydrogens attached to $\mathrm{N} 2$ (see Scheme 1 for atom labelling) by a halogen $(\mathrm{X}=\mathrm{Cl}, \mathrm{Br}$, I, or At). In the base pairs, only the hydrogens forming the hydrogen bonds were replaced; in all other structures, the corresponding hydrogens of all guanine substituents were replaced.

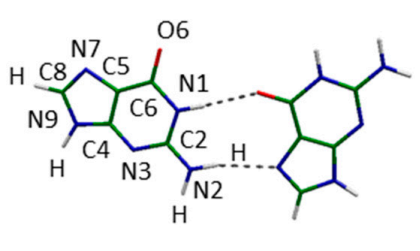

Hoogsteen base pair

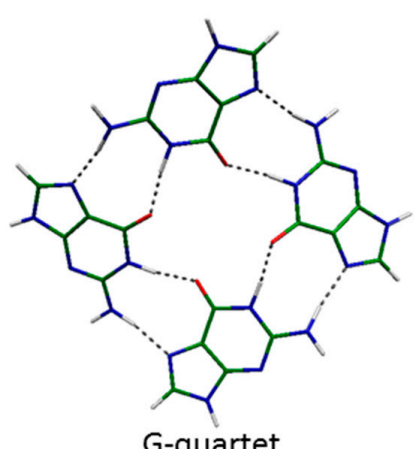

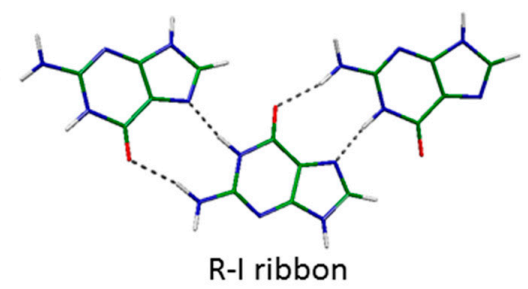

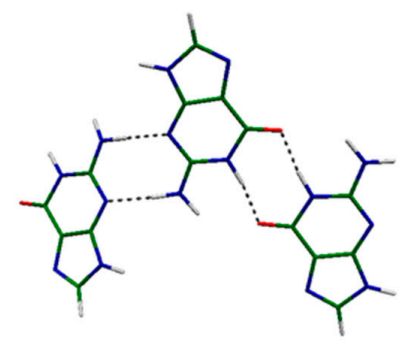

R-II ribbon

Scheme 1. Guanine structures considered in this work. Atom labelling is shown for one of the guanines in the Hoogsteen base pair.

The structures were optimised using the BLYP density functional $[13,15]$ augmented with a D3 dispersion term [47] with Becke-Johnson (BJ) damping [48,49], using the def2-SVP basis set [50]. We chose this functional in combination with the D3 dispersion term because the BLYP-D method showed excellent performance for systems of stacked nucleic acid base pairs and quartets [51]. Interaction energies, corrected for basis set superposition error (BSSE) using the counterpoise (CP) procedure [52], were computed at the BLYP-D3 level using the def2-TZVP basis set [50] 
(see Supplementary Materials Section S1 for details on the calculation of CP-corrected interaction energies and BSSE values). For the I1,I2-substituted R-I dimer, geometry optimisations were also carried out at the BLYP-D3/TZVP and B3LYP-D3/TZVP levels of theory. All calculations were done using the Orca 4.1.1 program [53,54] and used the def2/J auxiliary basis set [55] and integration Grid 7. The optimised structures are available in the Supplementary Materials (Table S2). Note that the def2 basis sets use the def2-ECP effective core potential for heavy atoms (in this case, iodine and astatine). In some cases, we encountered convergence problems with the SCF (self-consistent field), mainly during the CP calculations (see Supplementary Materials Section S2).

Criteria used to classify interactions as halogen bonds include (i) the requirement that the interatomic distance divided by the sum of the van der Waals radii $[56,57]$ of the constituent atoms, labelled the vdW ratio, is smaller than 1, and (ii) that the halogen bond angle is "not too far away" from being linear. Though halogen bonds tend to be linear, in previous work we found that significantly non-linear halogen bonds $\left(150-160^{\circ}\right)$ may exist in complex environments with competing interactions [32,33]. Thus, we deem angles over $150^{\circ}$ compatible with the interaction being a halogen bond.

Point group symmetry was determined using GaussView [58], in some cases using the loosest tolerance for detecting symmetry. For the trimers, cooperativity is defined as follows:

$$
E_{\text {coop }}=\Delta E_{\text {trimer }}^{C P}-\Delta E_{\text {dimer } 1}^{C P}-\Delta E_{\text {dimer2 }}^{C P}
$$

where $\Delta E_{\text {dimer } 1}^{C P}$ and $\Delta E_{\text {dimer } 2}^{C P}$ are the interaction energies of the constituting dimers in the trimer, and the " $\mathrm{CP}$ " superscripts indicate that the interaction energies are counterpoise-corrected.

\section{Conclusions}

We investigated the effect on structure and stability of replacing the hydrogen-bonding hydrogens in various guanine-based structures with halogens. The systems studied include guanine-guanine base pairs (in the Hoogsteen form), two different types of ribbons (R-I and R-II) consisting of two and three guanines, and guanine quartets. In the base pairs and R-I ribbons, which contain potential $\mathrm{N}-\mathrm{X} \bullet \bullet \bullet \mathrm{N}$ and $\mathrm{N}-\mathrm{X} \bullet \bullet \bullet \mathrm{O}$ interactions, a trend was observed to optimise the $\mathrm{N}-\mathrm{X} \bullet \bullet \bullet \mathrm{N}$ halogen bond at the expense of the $\mathrm{N}-\mathrm{X} \bullet \bullet \bullet \mathrm{O}$ interaction. This is the case for the $\mathrm{Br}-, \mathrm{I}-$, and At-containing base pairs, all halogenated R-I dimers, and the $\mathrm{Cl}-, \mathrm{Br}-$, and I-containing $\mathrm{R}-\mathrm{I}$ trimers. The $\mathrm{Cl}$-doped base pair has a distorted structure with a hydrogen bond but no halogen bonds. The undoped Hoogsteen base pair is not stable on the BLYP/def2-SVP potential energy surface; however, doping with heavier halogens ( $\mathrm{Br}$, I, At) restores the Hoogsteen pattern. In the At-doped R-I trimer, the hydrogens originally attached to $\mathrm{N} 1$ in the two halogen bond donating monomer units have moved to the adjacent O6, facilitating $\mathrm{O}-$ At $\bullet \bullet \bullet \mathrm{N}$ instead of the $\mathrm{N}-\mathrm{At} \bullet \bullet \bullet \mathrm{N}$ halogen bonds as well as forming an additional $\mathrm{N}-\mathrm{At} \bullet \bullet \bullet \mathrm{O}$ and N-At•••At halogen bond. The R-II trimers contain two different dimers, with either two potential $\mathrm{N}-\mathrm{X} \bullet \bullet \bullet \mathrm{N}$ (dimers 1) or two potential N-X $\bullet \bullet O$ interactions (dimers 2). The $\mathrm{Cl}$ - and Br-doped dimers 1 contain two equivalent $\mathrm{N}-\mathrm{X} \bullet \bullet \bullet \mathrm{N}$ halogen bonds, but in the I- and At-containing dimers, one of the interactions is lost. This is presumably due to the larger size of I and At, which makes it more difficult to accommodate both halogens in halogen-bonding positions. It is presumably more efficient to optimise one halogen bond instead. The dimers 2 all contain two equivalent $\mathrm{N}-\mathrm{X} \bullet \bullet \bullet \mathrm{O}$ halogen bonds. The halogen bond pattern is the same in the trimer as in its constituent dimers. The halogenated G-quartets display a range of halogen bond patterns. In some structures, the $\mathrm{N}-\mathrm{X} \bullet \bullet \bullet \mathrm{N}$ halogen bond is optimised at the expense of the $\mathrm{N}-\mathrm{X} \bullet \bullet \bullet \mathrm{O}$ interaction. However, in other structures, the $\mathrm{N}-\mathrm{X} \bullet \bullet \bullet \mathrm{O}$ halogen bond is optimised instead, whereas there are also structures where the $\mathrm{N}-\mathrm{X} \bullet \bullet \bullet \mathrm{N}$ and $\mathrm{N}-\mathrm{X} \bullet \bullet \bullet \mathrm{O}$ halogen bonds co-exist. Some structures manage to incorporate $\mathrm{X} \bullet \bullet \bullet X$ halogen bonds, either by adopting very non-planar structures or by moving the inner halogens from the N1 to the adjacent $\mathrm{O} 6$ atom. The latter structures become more important for the heavier atoms: whereas, for the $\mathrm{Cl}-$ and

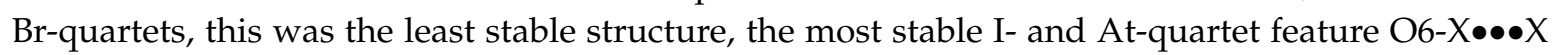


halogen bonds. In fact, the three most stable At-quartets feature O6-X $\bullet \bullet X$ halogen bonds. Our results indicate that halogenated bases can be incorporated into nucleic acid structures, which is relevant for the incorporation of unnatural halogenated bases into synthetic DNA and other nucleic acid structures.

In general, substitution of the hydrogen-bonding hydrogens by halogens leads to a decrease in stability, though the interaction energy of the At-doped R-I trimer just exceeds that of its hydrogen-containing counterpart, whereas the interaction energies of the three most stable At-doped quartets comfortably exceed that of the hydrogen-containing quartet. The At-doped R-II dimer 1 has an interaction energy nearly identical to the unsubstituted dimer $(-49.1 \mathrm{vs} .-49.5 \mathrm{~kJ} / \mathrm{mol})$. This shows that halogen bonds containing iodine or astatine can be similar, or stronger, in stability than corresponding hydrogen bonds. In all structures, the interaction energy increases with the increasing atomic number of the halogen. This is in disagreement with the results of Parker et al. for the canonical base pairs, where, in most cases, the Br-doped base pairs are more stable than the I-doped base pairs [16]. A recent study performing relativistic quantum calculations on complexes formed between halide anions and a series of $\mathrm{Y}_{3} \mathrm{C}-\mathrm{X}(\mathrm{Y}=\mathrm{F}$ to $\mathrm{X}, \mathrm{X}=\mathrm{I}, \mathrm{At})$ halogen bond donors revealed the weaker donation ability of $\mathrm{At}_{3} \mathrm{C}$-At compared to $\mathrm{I}_{3} \mathrm{C}$-I [59]. However, in most cases reported in the literature, heavier halogens form stronger halogen bonds.

Supplementary Materials: Supplementary Materials can be found at http://www.mdpi.com/1422-0067/21/18/ 6571/s1. Section S1: Calculation of CP-corrected interaction energies; Section S2: Conversion problems; Table S1: Selected geometrical and van der Waals ratios for the (1,2X-G)4 quartets $(\mathrm{X}=\mathrm{Br}$, I, At); Table S2: Cartesian coordinates of the undoped and halogenated reverse Hoogsteen base pairs, R-I and R-II ribbons, and G-quartets.

Author Contributions: Conceptualization, T.v.M.; Methodology, T.v.M.; Formal Analysis, N.J.T. and T.v.M.; Investigation, N.J.T.; Writing-Original Draft Preparation, T.v.M.; Writing-Review and Editing, T.v.M.; Supervision, T.v.M. All authors have read and agreed to the published version of the manuscript.

Funding: This research received no external funding.

Acknowledgments: We thank EaStCHEM for support via the EaStCHEM Research Computing Facility.

Conflicts of Interest: The authors declare no conflict of interest.

\section{References}

1. Cavallo, G.; Metrangolo, P.; Milani, R.; Pilati, T.; Priimagi, A.; Resnati, G.; Terraneo, G. The halogen bond. Chem. Rev. 2016, 116, 2478-2601. [CrossRef] [PubMed]

2. Kolář, M.H.; Hobza, P. Computer modeling of halogen bonds and other $\sigma$-hole interactions. Chem. Rev. 2016, 116, 5155-5187. [CrossRef] [PubMed]

3. Legon, A.C. The halogen bond: An interim perspective. Phys. Chem. Chem. Phys. 2010, 12, 7736-7747. [CrossRef] [PubMed]

4. Politzer, P.; Lane, P.; Concha, M.; Ma, Y.; Murray, J. An overview of halogen bonding. J. Mol. Model. 2007, 13, 305-311. [CrossRef]

5. Politzer, P.; Murray, J.S. Halogen bonding: An interim discussion. Chem. Phys. Chem. 2013, 14, 278-294. [CrossRef]

6. Wilcken, R.; Zimmermann, M.O.; Lange, A.; Joerger, A.C.; Boeckler, F.M. Principles and applications of halogen bonding in medicinal chemistry and chemical biology. J. Med. Chem. 2013, 56, 1363-1388. [CrossRef]

7. Wolters, L.P.; Schyman, P.; Pavan, M.J.; Jorgensen, W.L.; Bickelhaupt, F.M.; Kozuch, S. The many faces of halogen bonding: A review of theoretical models and methods. Wiley Interdiscip. Rev. Comput. Mol. Sci. 2014, 4, 523-540. [CrossRef]

8. Cates, E.L.; van Mourik, T. Halogen bonding with the halogenabenzene bird structure, halobenzene, and halocyclopentadiene. J. Comput. Chem. 2019, 40, 2111-2118. [CrossRef]

9. Saccone, M.; Catalano, L. Halogen Bonding beyond Crystals in Materials Science. J. Phys. Chem. B 2019, 123, 9281-9290. [CrossRef]

10. Otero-de-la-Roza, A.; LeBlanc, L.M.; Johnson, E.R. Dispersion XDM with Hybrid Functionals: Delocalization Error and Halogen Bonding in Molecular Crystals. J. Chem. Theory Comput. 2019, 15, 4933-4944. [CrossRef]

11. Auffinger, P.; Hays, F.A.; Westhof, E.; Ho, P.S. Halogen bonds in biological molecules. Proc. Natl. Acad. Sci. USA 2004, 101, 16789-16794. [CrossRef] [PubMed]

12. Metrangolo, P.; Resnati, G. Halogen versus hydrogen. Science 2008, 321, 918-919. [CrossRef] [PubMed] 
13. Becke, A.D. Density-functional exchange-energy approximation with correct asymptotic behavior. Phys. Rev. A 1988, 38, 3098-3100. [CrossRef] [PubMed]

14. Becke, A.D. Density functional thermochemistry. 3. The role of exact exchange. J. Chem. Phys. 1993, 98, 5648-5652. [CrossRef]

15. Lee, C.; Yang, W.; Parr, R.G. Development of the Colle-Salvetti correlation-energy formula into a functional of the electron density. Phys. Rev. B 1988, 37, 785-789. [CrossRef]

16. Parker, A.J.; Stewart, J.; Donald, K.J.; Parish, C.A. Halogen bonding in DNA base pairs. J. Am. Chem. Soc. 2012, 134, 5165-5172. [CrossRef]

17. Dapprich, S.; Komiromi, K.S.; Byun, K.; Morokuma, K.; Frisch, M.J. A new ONIOM implementation in Gaussian 98. Part I. The calculation of energies, gradients, vibrational frequencies and electric field derivatives. J. Mol. Struct. THEOCHEM 1999, 461, 1-21. [CrossRef]

18. Xu, L.; Sang, P.; Zou, J.-W.; Xu, M.-B.; Li, X.-M.; Yu, Q.-S. Evaluation of nucleotide C-BrO-P contacts from ONIOM calculations: Theoretical insight into halogen bonding in nucleic acids. Chem. Phys. Lett. 2011, 509, 175-180. [CrossRef]

19. Berman, H.M.; Westbrook, J.; Feng, Z.; Gilliland, G.; Bhat, T.N.; Weissig, H.; Shindyalov, I.N.; Bourne, P.E. The Protein Data Bank. Nucleic Acids Res. 2000, 28, 235-242. [CrossRef]

20. Møller, C.; Plesset, M.S. Note on an approximation treatment for many-electron systems. Phys. Rev. 1934, 46, 618-622. [CrossRef]

21. Frontera, A.; Bauzá, A. Halogen bonds in protein nucleic acid recognition. J. Chem. Theory Comp. 2020, 16, 4744-4752. [CrossRef] [PubMed]

22. Kolář, M.H.; Tabarrini, O. Halogen bonding in nucleic acid complexes. J. Med. Chem. 2017, 60, 8681-8690. [CrossRef] [PubMed]

23. Voth, A.R.; Hays, F.A.; Ho, P.S. Directing macromolecular conformation through halogen bonds. Proc. Natl. Acad. Sci. USA 2007, 104, 6188-6193. [CrossRef] [PubMed]

24. Paragi, G.; Guerra, C.F. Cooperativity in the self-assembly of the guanine nucleobase into quartet and ribbon structures on surfaces. Chem. Eur. J. 2017, 23, 3042-3050. [CrossRef]

25. Otero, R.; Schöck, M.; Molina, L.M.; Lægsgaard, E.; Stensgaard, I.; Hammer, B.; Besenbacher, F. Guanine quartet networks stabilized by cooperative hydrogen bonds. Angew. Chem. Int. Ed. 2005, 44, 2270-2275. [CrossRef] [PubMed]

26. Giorgi, T.; Grepioni, F.; Manet, I.; Mariani, P.; Masiero, S.; Mezzina, E.; Pieraccini, S.; Saturni, L.; Spada, G.P.; Gottarelli, G. Gel-like lyomesophases formed in organic solvents by self-assembled guanine ribbons. Chem. Eur. J. 2002, 8, 2143-2152. [CrossRef]

27. Gottarelli, G.; Masiero, S.; Mezzina, E.; Pieraccini, S.; Rabe, J.P.; Samorí, P.; Spada, G.P. The self-assembly of lipophilic guanosine derivatives in solution and on solid surfaces. Chem. Eur. J. 2000, 6, 3242-3248. [CrossRef]

28. Gottarelli, G.; Masiero, S.; Mezzina, E.; Spada, G.P.; Mariani, P.; Recanatini, M. The self-assembly of a lipophilic deoxyguanosine derivative and the formation of a liquid-crystalline phase in hydrocarbon solvents. Helv. Chim. Acta 1998, 81, 2078-2092. [CrossRef]

29. Xu, Z.; Yang, Z.; Liu, Y.; Lu, Y.; Chen, K.; Zhu, W. Halogen bond: Its role beyond drug-target binding affinity for drug discovery and development. J. Chem. Inf. Model. 2014, 54, 69-78. [CrossRef]

30. Clark, T.; Hennemann, M.; Murray, J.; Politzer, P. Halogen bonding: The $\sigma$-hole. J. Mol. Model. 2007, 13, $291-296$. [CrossRef]

31. Hogan, S.W.L.; van Mourik, T. Halogen bonding in mono- and dihydrated halobenzene. J. Comput. Chem. 2019, 40, 554-561. [CrossRef] [PubMed]

32. Hogan, S.W.L.; van Mourik, T. Corrigendum: Competition between hydrogen and halogen bonding in halogenated 1-methyluracil: Water systems. J. Comput. Chem. 2017, 38, 933. [CrossRef] [PubMed]

33. Hogan, S.W.L.; van Mourik, T. Competition between hydrogen and halogen bonding in halogenated 1-methyluracil: Water systems. J. Comput. Chem. 2016, 37, 763-770. [CrossRef] [PubMed]

34. Fleig, T.; Sadlej, A.J. Electric dipole polarizabilities of the halogen atoms in ${ }^{2} \mathrm{P}_{1 / 2}$ and ${ }^{2} \mathrm{P}_{3 / 2}$ states: Scalar relativistic and two-component configuration-interaction calculations. Phys. Rev. A 2002, 65, 032506. [CrossRef]

35. Guo, N.; Maurice, R.; Teze, D.; Graton, J.; Champion, J.; Montavon, G.; Galland, N. Experimental and computational evidence of halogen bonds involving astatine. Nat. Chem. 2018, 10, 428-434. [CrossRef] 
36. Liu, L.; Guo, N.; Champion, J.; Graton, J.; Montavon, G.; Galland, N.; Maurice, R. Towards a stronger halogen bond involving astatine: Unexpected adduct with Bu3PO stabilized by hydrogen bonding. Chem. Eur. J. 2020, 26, 3713-3717. [CrossRef]

37. Bhattacharyya, D.; Koripella, S.C.; Mitra, A.; Rajendran, V.B.; Sinha, B. Theoretical analysis of noncanonical base pairing interactions in RNA molecules. J. Biosci. 2007, 32, 809-825. [CrossRef]

38. Roy, A.; Panigrahi, S.; Bhattacharyya, M.; Bhattacharyya, D. Structure, stability, and dynamics of canonical and noncanonical base pairs: Quantum chemical studies. J. Phys. Chem. B 2008, 112, 3786-3796. [CrossRef]

39. van Mourik, T.; Gdanitz, R.J. A critical note on density functional theory studies on rare-gas dimers. J. Chem. Phys. 2002, 116, 9620-9623. [CrossRef]

40. Egli, M.; Lubini, P.; Pallan, P.S. The long and winding road to the structure of homo-DNA. Chem. Soc. Rev. 2007, 36, 31-45. [CrossRef]

41. Eschenmoser, A.; Loewenthal, E. Chemistry of potentially prebiological natural products. Chem. Soc. Rev. 1992, 21, 1-16. [CrossRef]

42. Chawla, M.; Abdel-Azeim, S.; Oliva, R.; Cavallo, L. Higher order structural effects stabilizing the reverse Watson-Crick guanine-cytosine base pair in functional RNAs. Nucleic Acid Res. 2013, 42, 714-726. [CrossRef] [PubMed]

43. Mittal, A.; Halder, A.; Bhattacharya, S.; Bhattacharyya, D.; Mitra, A. Reverse Watson-Crick purine-purine base pairs-The Sharp-turn motif and other structural consequences in functional RNAs. BioRchiv 2017, 098723. [CrossRef]

44. Burge, S.; Parkinson, G.N.; Hazel, P.; Todd, A.K.; Neidle, S. Quadruplex DNA: Sequence, topology and structure. Nucleic Acids Res. 2006, 34, 5402-5415. [CrossRef]

45. Meyer, M.; Steinke, T.; Brandl, M.; Sühnel, J. Density functional study of guanine and uracil quartets and of guanine quartet/metal ion complexes. J. Comput. Chem. 2001, 22, 109-124. [CrossRef]

46. van Mourik, T.; Dingley, A.J. Characterization of the monovalent ion position and hydrogen bond network in guanine quartets by DFT calculations of NMR parameters. Chem. Eur. J. 2005, 11, 6064-6079. [CrossRef]

47. Grimme, S.; Antony, J.; Ehrlich, S.; Krieg, H. A consistent and accurate ab initio parametrization of density functional dispersion correction (DFT-D) for the 94 elements H-Pu. J. Chem. Phys. 2010, 132, 154104. [CrossRef]

48. Becke, A.D.; Johnson, E.R. A density-functional model of the dispersion interaction. J. Chem. Phys. 2005, 123, 154101. [CrossRef]

49. Grimme, S.; Ehrlich, S.; Goerigk, L. Effect of the damping function in dispersion corrected density functional theory. J. Comput. Chem. 2011, 32, 1456-1465. [CrossRef]

50. Weigend, F.; Ahlrichs, R. Balanced basis sets of split valence, triple zeta valence and quadruple zeta valence quality for H to Rn: Design and assessment of accuracy. Phys. Chem. Chem. Phys. 2005, 7, 3297-3305. [CrossRef]

51. van der Wijst, T.; Fonseca Guerra, C.; Swart, M.; Bickelhaupt, F.M.; Lippert, B. A ditopic ion-pair receptor based on stacked nucleobase quartets. Angew. Chem. Int. Ed. 2009, 48, 3285-3287. [CrossRef] [PubMed]

52. Boys, S.F.; Bernardi, F. Calculation of small molecular interactions by differences of separate total energies-Some procedures with reduced errors. Mol. Phys. 1970, 19, 553-566. [CrossRef]

53. Neese, F. “The ORCA program system”, Wiley Interdiscip. Rev. Comput. Mol. Sci. 2012, 2, 73-78. [CrossRef]

54. Neese, F. Software update: The ORCA program system, version 4.0, Wiley Interdiscip. Rev. Comput. Mol. Sci. 2018, 8, e1327.

55. Weigend, F. Accurate Coulomb-fitting basis sets for H to Rn. Phys. Chem. Chem. Phys. 2006, 8, 1057-1065. [CrossRef]

56. Periodic Table-Astatine. Available online: http://www.rsc.org/periodic-table/element/85/astatine (accessed on 1 May 2020).

57. CRC. Handbook of Chemistry and Physics, 98th ed.; CRC Press: Boca Raton, FL, USA, 2009.

58. Dennington, R.; Keith, T.; Millam, J. Gauss View; Semichem, Inc.: Shawnee Mission, KS, USA, 2000.

59. Sarr, S.; Graton, J.; Montavon, G.; Pilmé, J.; Galland, N. On the interplay between charge-shift bonding and halogen bonding. Chem. Phys. Chem. 2020, 21, 240-250. [CrossRef]

(C) 2020 by the authors. Licensee MDPI, Basel, Switzerland. This article is an open access article distributed under the terms and conditions of the Creative Commons Attribution (CC BY) license (http://creativecommons.org/licenses/by/4.0/). 